\title{
308-nm excimer laser in the treatment of a localized recalcitrant form of perioral dermatitis: Case report
}

\author{
Catarina Queirós ${ }^{1}$, Luís Uva1, Paulo Filipe ${ }^{1,2}$
}

${ }^{1}$ Dermatology Department, Hospital de Santa Maria, Centro Hospitalar e Universitário de Lisboa Norte, Portugal, ${ }^{2}$ Faculty of Medicine, Universidade de Lisboa, Portugal

Corresponding author: Catarina Queirós, MD, E-mail: catarina.squeiros@gmail.com

\begin{abstract}
In the last two decades, 308-nm excimer laser has been increasingly recognized as a therapeutic alternative for several dermatological conditions, being currently FDA approved for the treatment of localized vitiligo and moderately severe localized psoriasis unresponsive to topical treatments. We describe the case of a 17 -year-old with a recalcitrant form of dermatitis occupying the entire perioral region, previously unresponsive to several treatments, who was treated with 308-nm excimer laser with an excellent result. 308-nm monochromatic excimer laser has several advantages over other types of phototherapy, including lower UV dose exposure, shorter courses of therapy and a better sparing of adjacent tissue. Although infrequently used, 308-nm excimer laser certainly has a vast potential in Dermatology, particularly regarding recalcitrant and localized inflammatory conditions, such as the one we present.
\end{abstract}

Key words: Laser therapy; Excimer laser; Dermatitis; Phototherapy

\section{INTRODUCTION}

In the last two decades, 308-nm excimer laser has been increasingly recognized as a therapeutic alternative for several dermatological conditions $[1,2]$. Although it is currently FDA approved only for the treatment of localized vitiligo and moderately severe localized psoriasis unresponsive to topical treatments, case reports have substantiated its use for localized severe atopic eczema, alopecia areata, cutaneous T-cell lymphoma, localized scleroderma, nail psoriasis and granuloma annulare, among other entities $[1,3]$.

\section{CASE REPORT}

We describe the case of a 17-year-old girl, Fitzpatrick skin type II, with no past relevant medical history, who was brought to our Dermatology Department complaining of erythema, desquamation, itching and a burning sensation in the perioral region for the last two months (Fig. 1). She had been previously treated with several topical agents, including topical steroids

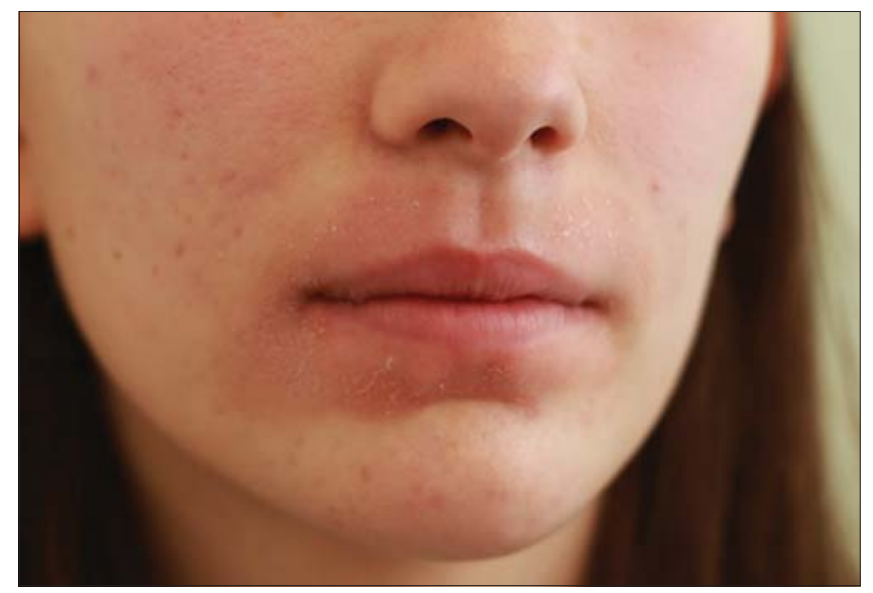

Figure 1: Before 308-nm excimer laser treatment. Localized dermatitis affecting the perioral area, with erythema and obvious desquamation.

(hydrocortisone $1 \%$ cream) and calcineurin inhibitors (tacrolimus $0.1 \%$ ointment), with no improvement. On physical examination, a form of dermatitis occupying the entire perioral region was seen, with sparing of the lips and oral mucosa. The patient had no lesions on the remaining skin. After parental consent, a decision

\footnotetext{
How to cite this article: Queirós C, Uva L, Filipe P. 308-nm excimer laser in the treatment of a localized recalcitrant form of perioral dermatitis: Case report. Our Dermatol Online. 2022;13(e):e5.

Submission: 02.06.2021; Acceptance: 26.11.2021

DOI: $10.7241 /$ ourd.2022e.5
} 


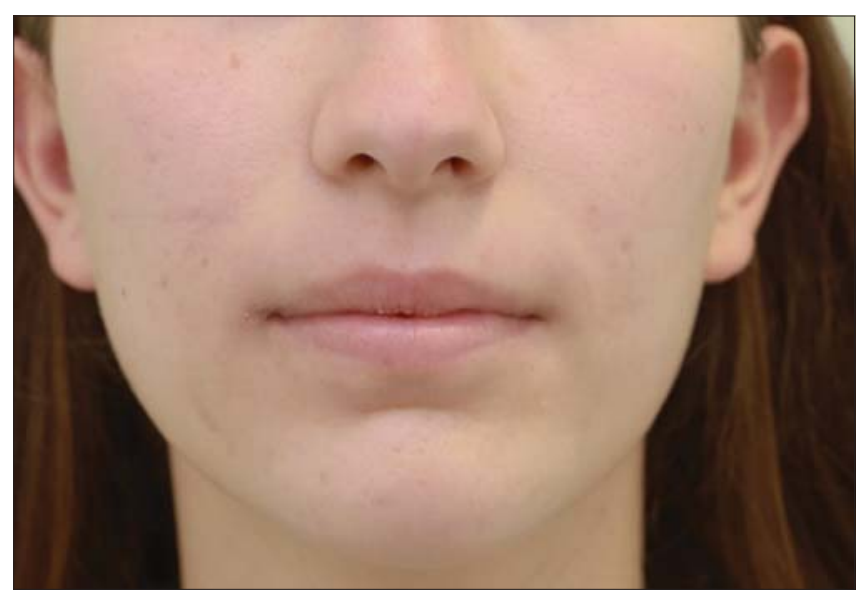

Figure 2: After 308-nm excimer laser treatment. Almost complete resolution of the erythema and desquamation, which was accompanied by disappearance of the itching and burning sensations.

to start 308-nm excimer laser was made. The patient was treated with $200 \mathrm{~mJ} / \mathrm{cm}^{2}$ on the first session

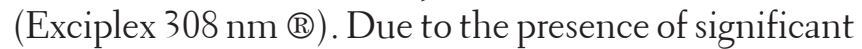
erythema, the dosage was reduced to $150 \mathrm{~mJ} / \mathrm{cm}^{2}$ on the second session (performed on day 3). On the next observation (day 5), a substantial improvement on overall appearance was seen, along with a significant relief of the itching and burning sensation (Fig. 2). Only a slight erythema with well defined borders was evident, related with the previous sessions. No more treatments were performed and the patient remains under follow up, with no recurrences detected during the following 3 months.

\section{DISCUSSION}

The excimer, also known as an "excited dimer", is formed by the combination of two atoms, namely xenon and chloride. The excitation of these dimers produces a 308-nm ultraviolet (UV) monochromatic coherent wavelength, which lies within the UVB spectrum and penetrates the epidermal cells and, afterwards, the fibroblasts [4-6]. The advantages of 308$\mathrm{nm}$ monochromatic excimer laser over other types of phototherapy include lower UV dose exposure, shorter courses of therapy and a better sparing of adjacent tissue, along with enabling access to difficult-to-reach sites $[1,4,6-8]$. The number of treatment sessions and cumulative UVB dosage needed for lesion clearance are also lower when compared with other forms of phototherapy, which may help to increase patient compliance and reduce potential risk for skin cancer [4].

Regarding localized forms of dermatitis, 308-nm excimer laser has been used with quite satisfactory results, both in children and in adults $[1,5]$. Treatment is usually well tolerated, with rare adverse reactions such as painful erythema, hyperpigmentation, erosions, koebnerisation and reactivation of herpes simplex infection [5].

Of course, the utility of this treatment modality is limited by its restricted access in certain settings, as well as the high costs associated [4]. Moreover, standardized protocols are lacking and the number of sessions needed and the duration of remissions remain unknown. Nonetheless, 308-nm excimer laser certainly has a vast potential in Dermatology, particularly regarding recalcitrant and localized inflammatory conditions, such as the one we present.

\section{Consent}

The examination of the patient was conducted according to the principles of the Declaration of Helsinki.

The authors certify that they have obtained all appropriate patient consent forms, in which the patients gave their consent for images and other clinical information to be included in the journal. The patients understand that their names and initials will not be published and due effort will be made to conceal their identity, but that anonymity cannot be guaranteed.

\section{REFERENCES}

1. Mehraban S, Feily A. 308nm Excimer Laser in Dermatology. J Lasers Med Sci. 2014;5:8-12.

2. Spencer JM, Hadi SM. The excimer lasers. J Drugs Dermatol. 2004;3:522-5.

3. Aubin F, Vigan M, Puzenat E, Blanc D, Drobacheff C, Deprez P, et al. Evaluation of a novel 308-nm monochromatic excimer light delivery system in dermatology: a pilot study in different chronic localized dermatoses. Br J Dermatol. 2005;152:99-103.

4. Beggs S, Short J, Rengifo-Pardo M, Ehrlich A. Applications of the Excimer Laser: A Review. Dermatol Surg. 2015;41:1201-11.

5. Nisticò SP, Saraceno R, Capriotti E, De Felice C, Chimenti S. Efficacy of monochromatic excimer light $(308 \mathrm{~nm})$ in the treatment of atopic dermatitis in adults and children. Photomed Laser Surg. 2008;26:14-8.

6. Passeron T, Ortonne J. Use of the 308-nm excimer laser for psoriasis and vitiligo. Clin Dermatol. 2006;24:33-42.

7. Mavilia L, Mori M, Rossi R, Campolmi P, Puglisi Guerra A, Lotti T. $308 \mathrm{~nm}$ monochromatic excimer light in dermatology: personal experience and review of the literature. G Ital Dermatol Venereol. 2008;143:329-37.

8. Morita A, Weiss M, Maeda A. Recent developments in phototherapy: treatment methods and devices. Recent Pat Inflamm Allergy Drug Discov. 2008;2:105-8.

Copyright by Catarina Queirós, et al. This is an open access article distributed under the terms of the Creative Commons Attribution License, which permits unrestricted use, distribution, and reproduction in any medium, provided the original author and source are credited.

Source of Support: Nil, Conflict of Interest: None declared. 